\title{
FIVE-YEAR RADIOGRAPHIC CHANGES OF RESIDUAL RIDGES UNDER MAXILLARY COMPLETE DENTURE AND ITS OPPOSING MANDIBULAR TWO IMPLANT-RETAINED OVERDENTURE WITH DIFFERENT RESILIENT ATTACHMENTS
}

\author{
Radwa M. K. Emera* and Elsayed A. Abdel-Khalek **
}

\begin{abstract}
Aim: This study aimed to radiographically compare the effect of different resilient attachments on maxillary and mandibular residual ridge changes after 5 years of using mandibular 2-implant retained overdentures.

Materials and methods: Eighteen completely edentulous male patients, with age ranging from 45 to 60 years, were included in the study. Maxillary complete dentures were constructed opposed to 2-implant retained mandibular overdentures. Patients were divided randomly into three equal groups according to type of attachment into; ball/socket (BOD) group, Locator attachment (LOD) group, and positioner attachment (POD) group. Maxillary and mandibular ridge resorption were determined by using the proportional area index method on the panoramic radiograph taken at time of overdenture insertion and at five years later.
\end{abstract}

Results: The minimal rate of ridge resorption was recorded for posterior maxillary ridges (MaxPRRR) followed by that of posterior mandibular ones (Mand-PRRR), while the highest resorption rate was recorded for anterior maxillary ridges (Max-ARRR). The study did not reveal significant difference in ridge resorpion between the resilient attachment systems.

Conclusion: Mandibular overdentures retained by two implants with the described attachment systems provide a similar and acceptable range of residual ridge resorption (RRR) after 5years of function. The reduced RRR with Locator attachments proved its ability to provide an equitable load on the implants and tissue bearing areas during function.

KEYWORDS: residual ridge resorption, resilient attachments, implant overdentures.

\footnotetext{
* Associate Professor, Removable Prosthodontics Department, Faculty of Dentistry, Mansoura University. Mansoura. Egypt

** Lecturer, Removable Prosthodontics Department, Faculty of Dentistry, Mansoura University. Mansoura. Egypt
} 


\section{INTRODUCTION}

Implant retained overdentures (IRODs) are a cost-effective and viable treatment for the rehabilitation of the edentulous mandible ${ }^{(1)}$. An overdenture supported by two unsplinted implants could be considered as the treatment of choice to overcome many of the problems encountered with conventional complete dentures (2). Patients used mandibular IRODs scored higher quality of life, satisfaction, and bite force than those used conventional dentures ${ }^{(1)}$.

To connect two implants with overdentures, resilient stud and bar attachments are available. However, the choice of the suitable attachment depends on the arch form, the available prosthetic space, the implant's inclination, and the retention value required ${ }^{(3-5)}$.

Unavoidable rotational movement of mandibular IRODs produces unfavorable occlusal loads distribution on the posterior mandiblular ridge and the anterior premaxilla ${ }^{(6,7)}$. Daas et al ${ }^{(8)}$. concluded that rigid attachment systems were accompanied by higher rocking movements whereas resilient attachments allowed a better distribution of load between denture bearing structures and dental implants during function.

Resilient attachment allows a pre-calculated amount of vertical movement when the prosthesis is fully seated ${ }^{(8,4)}$. When the patient bites, consequently, the inherent space between the patrix and matrix is lost to allow both implant and mucosal support of the denture during function ${ }^{3,4}$, 9). However, the amount of occlusal load transmitted by these attachments is a factor of their resiliency that determines their prosthetic complications ${ }^{(\mathbf{1 0}, 11,5)}$. In contrast to Jacobs et al. ${ }^{(12,13)}$ a study by Tymstra et al. ${ }^{(6)}$ concluded that patients treated with an IROD did not show higher residual ridge resorption (RRR) in anterior maxillary area in comparison to patients used a conventional complete denture.
Splinting two implants with a resilient hinging bar allows free overdenture rotation during function, that may cause posterior mucosal loading but anteriorly the occlusal load is carried by the implants ${ }^{(14-19)}$. Ball attachments have been considered as the gold standard in IRODs and successfully function even in resorbed edentulous ridges ${ }^{(20)}$. In comparison to stud-type attachments, most ball designs allow overdenture mobility along the axis connecting both implants, potentially leads to higher load on the denture bearing posterior ridges similar to bar attachment ${ }^{(\mathbf{9}, \mathbf{2 1})}$.

The unique design of the Locator patrix, unlike traditional ball abutments, is represented by a replaceable nylon insert on the intaglio surface of the overdenture ${ }^{(11,5)}$. This design makes the low profile and dual retentive features of the Locator attachment combined the best features of both ball and ERA attachments ${ }^{(11)}$. However, the original locator design allows food debris being lodged on the top of the abutment, potentially resulting in rapid distortion of the nylon insert with rapid loss of retention ${ }^{(11,21)}$.

New Locator designs (like Positioner attachment) were innovated with the absence of the central stud in the nylon inserts to permit movement about all axes, thus reducing loads applied to the implants and the supporting bone ${ }^{(\mathbf{5 , 2 1})}$.

Recently, Ahmad et al. ${ }^{(7)}$ concluded that IROD caused at least twice RRR as conventional dentures due to stronger bite force, they can potentially concentrate hydrostatic stress. Närhi et al. (22) documented that the anterior maxillary area is the weakest area of upper arch to withstand stresses and when using implants in the mandibular edentulous arch, trauma is inevitable especially when posterior denture support is lost over time. In this regard, the effect of these attachments on the antagonist jaw may be varied. A debate was reported in the literature on the impact of mandibular two IRODs with certain types of attachments on the opposing maxillary residual ridge resorption ${ }^{(10,17)}$. 
The aim of this clinical study was to radiographically compare the effect of different resilient attachments on maxillary and mandibular residual ridge changes after 5 years of using mandibular 2-implant retained overdentures. The null hypothesis was that the degree of residual ridge resorption, either maxillary ridge or posterior mandible, would not be affected by the attachment type.

\section{MATERIALS AND METHODS}

\section{Patient's selection:}

Eighteen completely edentulous male patients, with age ranging from 45 to 60 years of age, were selected from Removable Prosthodontics Department, Faculty of Dentistry, Mansoura University to participate in this study. The inclusion criteria were; At least one year of edentulism, Angle's class I skeletal arch relationship, sufficient bone quality and quantity to allow placement of interforaminal two dental implants. The exclusion criteria included; presence of bone metabolic disorders or any local or medical condition that adversely affect implant osseointegration. Patients with unclearly visible or missing anatomic landmarks of radiographic images were also excluded.

After informing each patient about the detailed treatment plan and his follow-up program, a singed informed consent was obtained before enrolment. This research work was approved by the Faculty Ethical Committee.

\section{Pre-surgical procedures:}

Routine medical and dental screening was performed for each patient. Conventional maxillary and mandibular complete dentures were fabricated by using balanced lingualized occlusion with no anterior teeth contact in the maximal intercuspal position. Preoperative radiographic planning of the implant sites was performed by using doublescan cone beam computed tomography (CBCT).
Accurate location for implant measurements based on bone height (vertically) and thickness (buccolingually) were determined using the planning software (OnDemand software). An acrylic replica of the patient's mandibular denture was fabricated to be used as a radiographic template with markers and a computer-fabricated surgical guide was used for the osteotomy drilling.

\section{Surgical procedures}

- Antibiotic therapy was started 1 hour before surgery and was continued for 6 days later. Chlorohexdine mouth was rinsed for 1 minute before surgery. Local anesthesetic solution (lidocaine 2\% with 1:100,000 epinephrine) was infiltrated at the canine areas bilaterally. A full-thickness mucoperiosteal flap was elevated to facilitate proper visualization of lingual cortical bone.

- The pilot drill was directed to crestal bone of the mandible guided by the surgical guide. A sequenced drilling procedure was followed to prepare an osteotomy site for two titanium implants of $13 \mathrm{~mm}$ in length and $4 \mathrm{~mm}$ diameter (Dyna implants. Germany). Implants were inserted in the prepared osteotomy and delayed loading protocol was used. Mandibular complete denture was relined with tissue conditioner, which was replaced with autopolymerized soft liner (Promedica, Germany) after 5 days.

After 3-months osseointegration period, patients were randomly assigned into three equal groups (each consists of six patients) according to type of attachment used to retain the mandibular overdentures as follows: Fig. 1

- Group LOD: $2.25 \mathrm{~mm}$ supragingival Locator abutment with blue nylon insert (very low retention: $680 \mathrm{~g}$ ).

- Group POD: $2.3 \mathrm{~mm}$ supragingival Positioner abutment with nylon insert (retention: 300-500gf). 

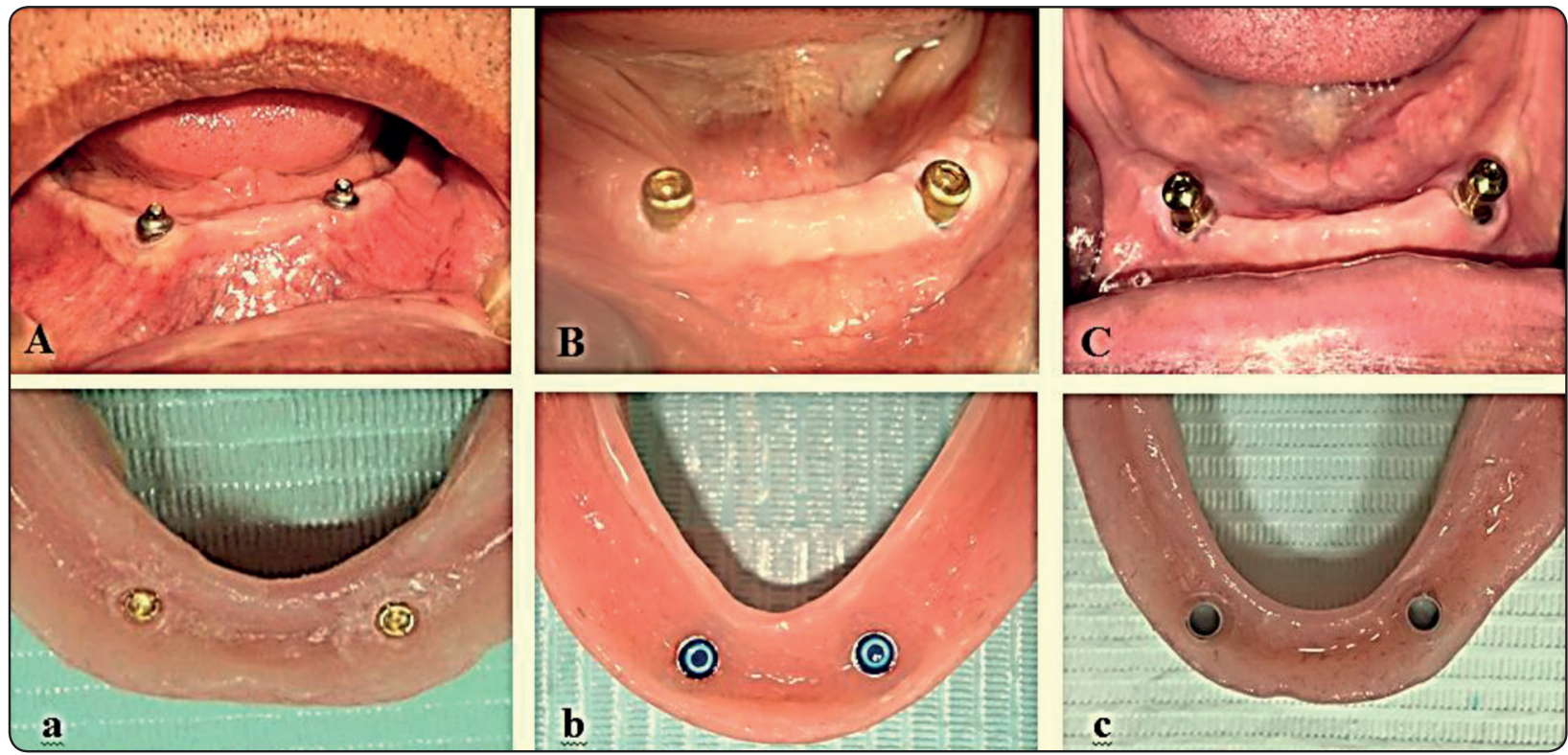

Fig. (1) Study groups include; (A) Ball patrix with (a) smart gold matrix; (B) Locator female abutment with (b) nylon insert; and (C) Positioner Abutment with (c) nylon insert.

- Group BOD: ball/smart gold socket attachment.

- The ontaglio surface of mandibular overdenture was relieved opposite to the attachment abutments and then direct pick-up procedures were followed. Occlusion was refined to ensure proper occlusal contact.

- The patients were then scheduled for postinsertion visits and every 12-months recall appointments for replacement of nylon inserts or activation of gold matrices. After checking the occlusal contacts, denture relining was planned during the 5-year observation period.

\section{Radiographic evaluation:}

-Maxillary and mandibular residual ridges resorption was evaluated using two consecutive digital panoramic radiographs that were taken for each patient immediately after implant loading (T0) and at 5 years later (T5).

-For standardization of all radiographic images, the panoramic unit was adjusted at $(69 \mathrm{kV})$ with an exposure time of (16s) and a constant current of $(16 \mathrm{~mA} / \mathrm{s})$ while the patient bites on a custom made acrylic occlusal stent connected to the unit chin stabilizer.

-RRR was evaluated by using the proportional area index method, previously described by Kreisler et al. (23) for maxillary arch and by Wilding et al. (24) for posterior mandibular ridge measurements. Reference landmarks and points were located on right and left sides of the arches and were traced digitally using software (Autodesk, AutoCad version.2014, 64.bit) Fig. 2

-The details of area index method was described in previous studies ${ }^{(15,18)}$. The ridge locations included maxillary anterior (max-ARRR), maxillary posterior (max-PRRR), and mandibular posterior (mand-PRRR) residual ridges.

-The following points were located on the maxillary arch: the articular tubercle $\mathrm{T}$, the most inferior points of orbit $\mathrm{O}$ and anterior nasal spine $\mathrm{S}$. The unilateral radiographic areas provided by 


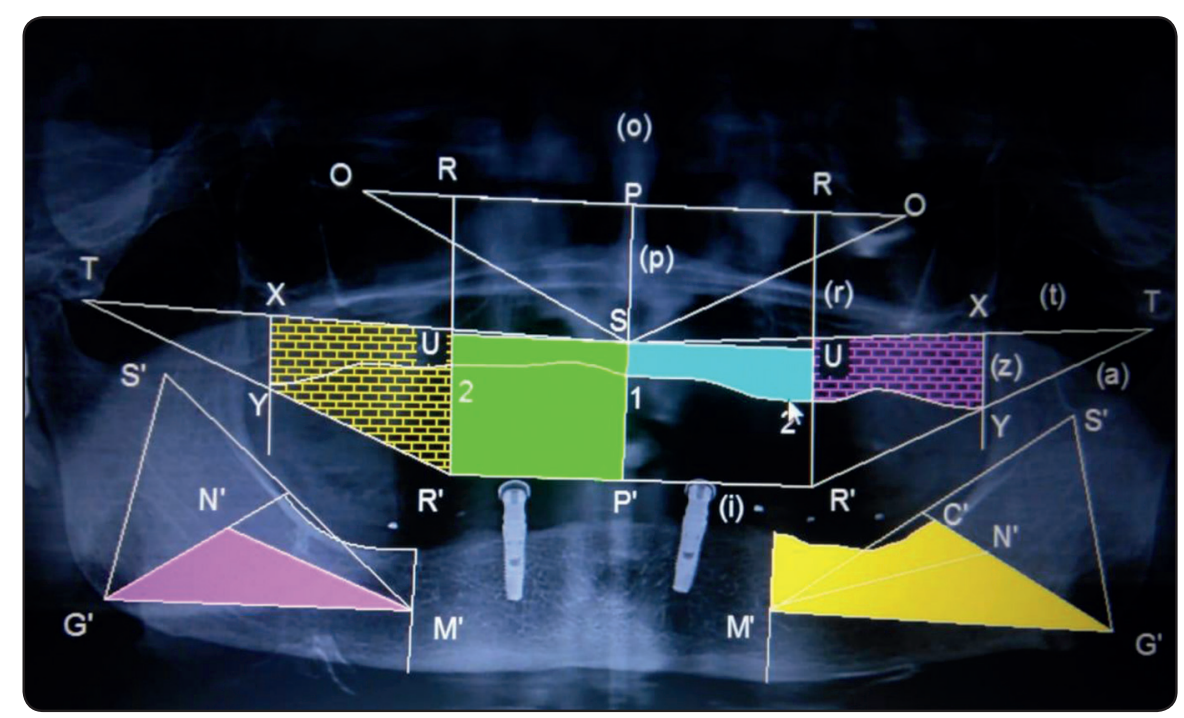

Fig. (2) Traced panoramic x-ray

joining the reference points and lines resulted in anatomic /reference areas represented as S12U/ SP'R'U, XY2U/XYR'U for max-ARRR, maxPRRR, respectively.

-In the mandible, the following points were identified: the most inferior point of the mental foramen $\mathrm{M}$, sigmoid notch $\mathrm{S}$ and gonion $\mathrm{G}$. The unilateral radiographic areas provided by joining the reference points and lines resulted in anatomic /reference areas represented as G'C'F'M'/G'N'M' for mand-PRRR, respectively.

- Calculations of the bone ratios were done using proportional area for each side and the mean difference of ratios bilaterally was calculated between to determine RRR.

-The anterior and posterior maxillary RRR was calculated by subtracting $\mathrm{R}$ at $\mathrm{T} 5$ from $\mathrm{R}$ at $\mathrm{T} 0$. A positive difference indicated bone resorption, and negative difference indicated bone apposition.

-The change in bone areas (which represents bone resorption along the whale ridge length) estimates the change in ridge height. The approximate changes in height can be calculated by dividing the change in bone area by the average ridge length and then the annual change in ridge height can be calculated, subsequently.

\section{Statistical analysis:}

Results were collected by a single calibrated examiner (mean of three measures). All data were analyzed with SPSS program version 21 Statistical Packages for Social Science. Shapiro-Wilk test was used to examine the normal distribution of data. The data was non-parametric and the descriptive statistics were expressed in the form of Median (minimum-maximum). Kruskal-Wallis test was used to compare ridges resorpion between the three groups. Friedman test was applied to compare different residual ridges resorption within each group followed by Wilcoxon Signed Ranks test for pair wise comparisons. Spearman's test of correlation was used to evaluate the correlation between different residual ridges resorption within each group.

\section{RESULTS}

Descriptive statistics of RRR were represented in table (1). Least median values of RRR were recorded for max-PRRR followed by that of mandPRRR, while the highest resorption values were that of max-ARRR.

Kruskal-Wallis test revealed insignificant difference of RRR between the three groups. 
Friedman test showed a significant difference of recorded RRR of different ridge locations within each group.

Significant difference was recorded in RRR between each two ridge locations within each group as shown in table (2) using Wilcoxon Signed Ranks test. Spearman's test of correlation showed a significant correlation between maxARRR and max-PRRR in LOD and BOD groups. While significant correlation between max-ARRR and mand-PRRR was only found in POD group as shown in table (3). No correlation was found between max-PRRR and mand-PRRR.

Mean change in bone area was $24.34 \mathrm{~mm}^{2}, 7.94$ $\mathrm{mm}^{2}$ and $18.68 \mathrm{~mm}^{2}$ for max-ARRR max-PRRR and mand-PRRR respectively in LOD group and $23.55 \mathrm{~mm}^{2}, 4.77 \mathrm{~mm}^{2}$ and $22.44 \mathrm{~mm}^{2}$ respectively for POD group, while BOD group recoded 23.76 $\mathrm{mm}^{2}, 9.24 \mathrm{~mm}^{2}$ and $24.54 \mathrm{~mm}^{2}$, respectively.

TABLE (1): Descriptive statistics and comparisons of residual ridges resorption of the three groups.

\begin{tabular}{|c|c|c|c|c|}
\hline Rroup & $\begin{array}{c}\text { Ant. Maxillary } \\
\text { M(min-max })\end{array}$ & $\begin{array}{c}\text { Post. Maxillary } \\
\text { M(min-max })\end{array}$ & $\begin{array}{c}\text { Post.Mandibular } \\
\mathrm{M}(\min -\max )\end{array}$ & $\begin{array}{c}\text { Friedman test } \\
(\mathrm{P} \text { value })\end{array}$ \\
\hline Locator & $0.95(0.70-1.25)$ & $0.27(-0.20-0.55)$ & $0.47(0.20-0.65)$ & $0.002 *$ \\
\hline Positioner & $0.95(0.60-1.15)$ & $0.02(-0.25-0.60)$ & $0.65(0.20-0.85)$ & $0.002 *$ \\
\hline Ball \& socket & $0.97(0.60-1.30)$ & $0.40(-0.15-0.60)$ & $0.75(0.25-0.95)$ & $0.002 *$ \\
\hline Kruskal-Wallis (P value) & 0.90 & 0.96 & 0.15 & \\
\hline
\end{tabular}

M: Mean min:minimum max :maximum RRR: Residual ridge resorption

Ant.Anterior Post:Posterior *: Significant

TABLE (2): Wilcoxon Signed Ranks test of pair wise comparisons of different residual ridges resorption within each group.

\begin{tabular}{|c|c|c|c|}
\hline & $\begin{array}{c}\text { Ant. Maxillary Vs } \\
\text { Post. Maxillary } \\
\text { (P value) }\end{array}$ & $\begin{array}{c}\text { Ant. Maxillary Vs } \\
\text { Post. Madibular } \\
\text { (P value) }\end{array}$ & $\begin{array}{c}\text { Post. MaxillaryVs } \\
\text { Post. Madibular } \\
\text { (P value) }\end{array}$ \\
\hline Locator & $0.027^{*}$ & $0.027^{*}$ & $0.027^{*}$ \\
\hline Positioner & $0.027^{*}$ & $0.026^{*}$ & $0.028^{*}$ \\
\hline Ball \& socket & $0.027^{*}$ & $0.028^{*}$ & $0.028^{*}$ \\
\hline
\end{tabular}

*: Significant

TABLE (3): Spearman's test of correlation between different residual ridges resorption within each group.

\begin{tabular}{|c|c|c|c|}
\hline \multicolumn{2}{|c|}{} & Ant. Maxillary and Post. Maxillary & Ant. Maxillary and Post. Madibular \\
\hline Locator & (r value) & 0.812 & 0.754 \\
& (p value) & $0.050^{*}$ & 0.084 \\
\hline Positioner & ( value) & 0.754 & 0.986 \\
& ( v value) & 0.084 & $0.000^{*}$ \\
\hline Ball \& socket & ( value) & 0.986 & 0.771 \\
& (p value) & $0.000^{*}$ & 0.072 \\
\hline
\end{tabular}

\section{*: Significant}




\section{DISCUSSION}

The present study evaluated the effect of different resilient attachments for mandibular twoIRDs opposed to maxillary complete denture on RRR after five years of overdenture use.

The ultimate goals for selecting a suitable attachment system for IRODs are minimal complications and even distribution of forces between the mechanical structures and biological supporting tissues ${ }^{(4,9)}$. However, the selected attachment type may cause different degrees of stability that may cause different prosthetic complications on the opposing maxillary complete denture ${ }^{(9,10)}$.

The overdenture attachments may allow rotational movement upon function thus they may cause excessive forces on the opposing arch (17). Resilient type of connecting mechanism is known to show a noticeable amount of vertical displacement and might show less technical complications such as reduced mechanical damage to the implant and prosthetic components ${ }^{(5,9,11,21)}$.

Female patients were excluded at the beginning of this study as they have a higher risk of bone resorption under the influence of hormonal factors ${ }^{(18,19)}$. Bilateral balanced lingualized occlusion has been recommended in removable implant overdentures especially for patients with opposing complete maxillary denture to gain better load distribution and to enhance occlusal stability ${ }^{(6,10,22 ; 25)}$.

RRR could be reliably measured on panoramic radiographs by the proportional area index method $(\mathbf{6}, \mathbf{1 2}, \mathbf{1 3}, \mathbf{2 3 )}$. This well-established method was referred to the value between the two outlined areas in the jaws, one area based on landmarks not susceptible to resorption while the other was determined by the alveolar ridge extent $\left({ }^{18,}, 19,25\right)$. It decreases problems associated with distortion and magnification in rotational radiographs, and compensates errors of head positioning ${ }^{(23,25)}$.
The mean ridge length recorded in this study was $24.95 \mathrm{~mm}, 37.25 \mathrm{~mm}$ and $40.95 \mathrm{~mm}$ for anterior maxillary, posterior maxillary and posterior mandibular residual ridges respectively. The study reported insignificant differences between the three attachment systems. This is in agreement with a systematic review of Rutkunas et al. ${ }^{(10)}$ that did not reveal evidence of accelerated maxillary RRR with overdentures using various types of resilient attachment. The resilient liner attachment permits vertical, hinge and horizontal movements of mandibular overdenture and makes them totally mucosa supported, thus increasing ridge resorption ${ }^{(19)}$.

The current results showed a slight increase with max-ARRR in comparison to max-PRRR and mand-PRRR. The increased RRR with BOD, although not significantly different, may be recoded because the ball attachment provides an effective retention and anterior stability to overdentures, the patients move their mandibles in an anterior direction to benefit from the generated occlusal forces ${ }^{(9,13,19)}$. Consequently, higher anterior occlusal forces caused by BOD may favor more resorption of the anterior maxillary ridge ${ }^{(17,18)}$.

The change in RRR recoded in the present study couldn't be compared directly to the results of the previous studies because of the differences in the attachment types. However, it is possible to compare the estimated annual bone loss in this study to other studies that had been used attachments with similar retentive mechanism.

As the hinging bar permits a noticeable vertical displacement with rotational movement to the overdenture similar to ball/socket attachment, comparing the findings of the current study to previous studies could be possible ${ }^{(16,17)}$.

The present study recorded $0.19 \mathrm{~mm}$, and $0.05 \mathrm{~mm}$ for LOD, $0.19 \mathrm{~mm}$, and $0.004 \mathrm{~mm}$ for POD, $0.194 \mathrm{~mm}$ and $0.08 \mathrm{~mm}$ for BOD as the average annual max-ARRR and max-PRRR, respectively. 
The present findings agree with Elsyad and colleagues ${ }^{(18)}$ in a 5-year study, reported $0.26 \mathrm{~mm}$ and $0.12 \mathrm{~mm}$ annual max-ARRR for combined implant-mucosal support and totally mucosa supported group, respectively. In the same study, the authors reported $0.09 \mathrm{~mm}$ and $0.1 \mathrm{~mm}$ annual max-PRRR for combined implant-mucosal support and totally mucosa supported group, respectively. The max-ARRR with clip-retained mandibular overdentures is expected to be higher than ball attachment. The horizontal stability provided by the bar encourages the patients to incise anteriorly with maximum bite force comparable to that applied by natural dentition which make the maxillary dentures unstable ${ }^{(14)}$.

Locator attachment allows a resilient connection between abutment and overdenture with a limit of $1.2 \mathrm{~mm}$ in vertical direction and $8^{\circ}$ in all directions, hence, the overdenture is totally mucosal support as the case of complete dentures ${ }^{(11)}$. Therefore, RRR in LOD and POD groups can be compared with average ridge height reduction for soft liner group in the previous studies ${ }^{(18,19)}$ therefore; the occlusal forces transmitted to the anterior portion of the maxillary ridge were reduced and associated with minimal maxillary RRR.

Despite insignificant differences, the present study found more pronounced max-PRRR with BOD which can be attributed to the stronger bite force generated by the mandibular IRODs that could potentially concentrate hydrostatic stress and cause greater RRR compared to a conventional dentures ${ }^{(1,7,12,13)}$.

The present study recorded average annual mand-PRRR $0.09 \mathrm{~mm}, 0.13 \mathrm{~mm}$, and $0.15 \mathrm{~mm}$ for LOD, POD, and BOD group, respectively. The current study presented mand-PRRR that could be compared to another 7-year study ${ }^{(19)}$ that measured $0.11 \mathrm{~mm}$ and $0.2 \mathrm{~mm}$ annual vertical RRR for combined implant-mucosal support and totally mucosa supported group, respectively. The better load distribution and equitable force provided by Locator system may explain the reduced mandPRRR in LOD group ${ }^{(5,9)}$.

The present study revealed significant differences between different ridge locations within each attachment groups while RRR was always more in max-ARRR. These findings are similar to other studies of IRODs ${ }^{(\mathbf{1 8}, 23)}$ that reported more ridge resorpion of anterior part of maxilla than in the posterior part as a result of the higher occlusal forces directed to the anterior maxillary area.

The finding of this study revealed a strong positive correlation between max-ARRR and max-PRRR in LOD ( $r=0.812)$ and BOD ( $r=0.986)$ groups. These results concur with Abd El-Dayem et al ${ }^{(17)}$ reported an increased in max-ARRR and maxPRRR in the mainly mucosa-supported overdenture after 2 years.

The strong positive correlation between maxARRR and mand-PRRR was only found in POD $(r=0.986)$ group. The correlation in RRR between different ridge locations seemed to be related to the type of stability provided by each attachment system. Accordingly, the process of RRR may occur in either two different ways; apical shifting of the entire cortical layer or thinning of the cortical layer ${ }^{(7)}$. With regard to mand-PRRR, it may be associated with the type of prosthesis support but could happen irrespective of type of removable prosthesis ${ }^{(6,25)}$.

From biomechanical point of view, the magnitude and direction of the posterior occlusal load/unit area under mandibular IRODs may cause greater mandPRRR than in the maxilla ${ }^{(25)}$. The maxillary denture base, covering the palate, provides greater tissuesupport for maxillary dentures, in contrast to the smaller tissue-bearing area available for mandibular one.

On the other hand, some researchers stated that anterior maxillary bone provides a poorer support for prosthetic rehabilitation than mandibular 
cortical ridge ${ }^{(22,26)}$. Generally, the bone resorption rate decreases in patients with atrophied mandibular ridges where dentures rest mainly on basal bone ${ }^{(15)}$.

The presence of a large inter-individual variability of the annual RRR could be related to the multifactorial etiology of bone resorption ${ }^{(13,15)}$. However, reduced rate of RRR in the present study may be attributed to the routine every year follow-up visits to check the fit and occlusion of the denture. Theses recall visits monitored the bone remodeling which takes one year after prosthesis delivery to follow the shape of the denture-fitting surface, after which the forces may be better distributed with less RRR in the next few years ${ }^{(7)}$.

In this regard, some researchers recommended the need for relining that might increase after the first years of service, especially with bar attachments $(\mathbf{1 0}, \mathbf{1 2})$. This agrees with studies, which documented that the loss of posterior support for the mandibular prosthesis can lead to significant maxillary RRR and soft tissue inflammation ${ }^{(11,16,17)}$.

Although the findings of the current study were not site specific and based on calculations to estimate RRR, practitioners may use this knowledge to tailor the suitable prosthetic design for every patient in order to reduce RRR. The present study had some limitations including; the relatively small sample size, only male participants were included, and the influence of confounding variables is not wellcontrolled.

\section{CONCLUSION}

Within the limitation of this clinical study, it could be concluded that;

- Mandibular overdentures retained by two implants with the described attachment systems provide a similar and acceptable range of residual ridge resorption after 5years of function.

- The slightly increased maxillary RRR associated with ball/socket system suggested its use with sufficient ridge height and opposing maxillary ridge of higher bone density.

- The reduced RRR with Locator attachment proved its ability to provide an equitable load on the implants and tissue bearing areas during function.

- Further studies are required to investigate the role of prosthetic maintenance of the described attachments on the rate and pattern of RRR.

\section{REFERENCES:}

1- Kutkut A, Bertoli E, Frazer R, Pinto-Sinai G, Fuentealba Hidalgo R, Studts J. A systematic review of studies comparing conventional complete denture and implant retained overdenture. J Prosthodont Res. Jan 2018;62(1):19

2- Feine JS, Carlsson GE, Awad MA, Chehade A, Duncan WJ, Gizani S, et al. The McGill consensus statement on overdentures. Mandibular two-implant overdentures as first choice standard of care for edentulous patients. Gerodontology 2002;19:3-4.

3- Vasant R, Vasant M K. Retention systems for implant-retained overdentures. Dent Update 2013; 40: 28-31.

4- Laverty D,Green D, Marrison D, Addy L, Thomas M. Implant retention systems for implant-retained overdentures. Br Dent J. 2017 Mar 10;222(5):347-359.

5- Baba N, Al-Harbi F, AlRumaih H, AlShehri A. A Novel Extended Range Attachment System to Retain Implant Overdentures: A Clinical Report. J Prosthodont 2018; 5: $1-7$.

6- Tymstra N, Raghoebar G.M, Vissink A. , Meijer H.J. Maxillary anterior and mandibular posterior residual ridge resorption in patients wearing a mandibular implantretained overdenture. J Oral Rehabil 2011; 38:509-516.

7- Ahmad R. The Relationship of mandibular morphology with residual ridge resorption associated with implant-retained overdentures. Int J Prosthodont 2016; 29: 573-580.

8- Daas M, Dubois G, Bonnet A.S, Lipinski P, Rignon-Bret C. A complete finite element model of a mandibular implantretained overdenture with two implants: Comparison between rigid and resilient attachment configurations. Medical Engineering \& Physics 2008 ;30: 218-225. 
9- Cepa S, Koller B, Spies BC, Stampf S, Kohal R-J. Implant retained prostheses: ball vs. conus attachments - A randomized controlled clinical trial. Clin. Oral Impl. Res. 2017; 28: 177-185.

10- Rutkunas V, Mizutani H, Peciuliene V, Bendinskaite R, Linkevicius T. Maxillary complete denture outcome with two-implant supported mandibular over- dentures. A systematic review. Stomatologija 2008;10:10-5.

11- Kleis W, Kämmerer P. Hartmann S, Al-Nawas B, Wagner W. A Comparison of Three Different Attachment Systems for Mandibular Two-Implant Overdentures: One-Year Report. Clinical Implant Dentistry and Related Research 2010;12(3): 209-219.

12- Jacobs R, Schotte A, van Steenberghe D, Quirynen M, Naert I. Posterior jaw bone resorption in osseointegrated implantsupported overdentures. Clin Oral Implants Res 1992;3:63-70.

13- Jacobs R, van Steenberghe D, Nys M, et al. Maxillary bone resorption in patients with mandibular implantsupported overdentures or fixed prostheses. J Prosthet Dent. 1993;70:135-140.

14- Thiel CP, Evans DB, Burnett RR. Combination syndrome associated with a mandibular implant-supported overdenture: a clinical report. J Prosthet Dent. 1996; 75:107-13.

15- Kordatzis K, Wright PS, Meijer HJ. Posterior mandibular residual ridge resorption in patients with conventional dentures and implant overdentures. Int J Oral Maxillofac Implants. 2003; 18: 447-452.

16- Assad AS, Abdeldaye MA, Badawy MM. Comparison between mainly mucosa supported and combined mucosaimplant supported mandibular overdentures. Implant Dent. 2004;13:386-394.

17- Abd El-Dayem MA, Assad AS, Abdel-Ghany MM. The effect of different mandibular dentures on antagonistic maxillary ridge. Implant Dent 2007;16:421-9.
18- ELsyad M, M. Ashmawy M, Faramawy A. The influence of resilient liner and clip attachments for bar-implantretained mandibular overdentures on opposing maxillary ridge. A 5-year randomised clinical trial. Journal of Oral Rehabilitation 2014 41; 69-77.

19- ELsyad M, Mohamed , Shawky A. Posterior Mandibular Ridge Resorption Associated with Different Retentive Systems for Overdentures: A 7-Year Retrospective Preliminary Study. Int J Prosthodont 2017;30:260-265.

20- Al-Ghafli SA, Michalakis KX, Hirayama H, Kang K. The in vitro effect of different implant angulations and cyclic dislodgement on the retentive properties of an overdenture attachment system. J Prosthet Dent 2009;102:140-147.

21- Shah K, Yilmaz B, McGlumphy E..Fabrication of a mandibular implant supported overdenture with a new attachment system: A review of current attachment systems. Int J Prosthodont 2017;30:245-247.

22- Narhi TO, Geertman ME, Hevinga M, Abdo H, Kalk W. Changes in the edentulous maxilla in persons wearing implant-retained mandibular overdentures. J Prosthet Dent. 2000;84: 43-49.

23- Kreisler M, Behneke N, Behneke A, d'Hoedt B. Residual ridge resorption in the edentulous maxilla in patients with implant-supported mandibular overdentures: an 8-year retrospective study. Int J Prosthodont 2003;16: 295-300.

24- Wilding R, Levin I, Pepper R. The use of panoramic radiographs to measure alveolar bone areas. J Oral Rehabil. 1987;14:557-567.

25- Khuder T, Yunus N, Sulaiman E, Ibrahim N, Khalid T, Masood M. Association between occlusal force distribution in implant overdenture prostheses and residual ridge resorption. Journal of Oral Rehabilitation 2017; 44: 398-404

26- Klemetti E. Is there a certain number of implants needed to retain an overdenture? J Oral Rehabil 2008;35(1):80-84. 